\title{
Distribution and determinants of patient satisfaction in oncology: A review of the literature
}

\author{
This article was published in the following Dove Press journal: \\ Patient Preference and Adherence \\ 2I August 2009 \\ Number of times this article has been viewed
}

\section{Christopher G Lis \\ Mark Rodeghier \\ Digant Gupta}

Cancer Treatment Centers of America ${ }^{\circledR}$ at Midwestern Regional Medical Center, 2610 Sheridan Road, Zion, IL, 60099, USA
Correspondence: Christopher G Lis Cancer Treatment Centers of America ${ }^{\circledR}$, 2610 Sheridan Road, Zion, IL 60099, USA

Tel + I 8477464328

Fax + I 8477464329

Email christopher.lis@ctca-hope.com

\begin{abstract}
Cancer is one of the leading causes of morbidity and mortality in the United States. It places considerable mental, physical, and emotional stress on patients and requires them to make major adjustments in many key areas of their lives. As a consequence, the demands on health care providers to satisfy the complex care needs of cancer patients increase manifold. Of late, patient satisfaction has been recognized as one of the key indicators of health care quality and is now being used by health care institutions for monitoring health care improvement programs, gaining accreditation, and marketing strategies. The patient satisfaction information is also being used to compare and benchmark hospitals, identify best-performance institutions, and discover areas in need of improvement. However, the existing literature on patient satisfaction with the quality of cancer care they receive is inconsistent and heterogeneous because of differences in study designs, questionnaires, study populations, and sample sizes. The aim of this review was therefore to systematically evaluate the available information on the distribution and determinants of patient satisfaction in oncology.
\end{abstract}

Keywords: patient satisfaction, determinants, oncology

\section{Introduction}

In recent years, awareness has risen of how patients perceive the quality of their health care. ${ }^{1,2}$ Consequently measuring patient satisfaction has become an important tool to gain attention and value amongst the health care consumers as well as competitors. It has become increasingly important for health care professionals to systematically measure patients' perceptions of and satisfaction with their care. Measuring patient satisfaction encompasses evaluating patient's perceptions and determining whether they felt that their needs were met. Evaluation of patient satisfaction in oncology involves a diverse array of methodologies including in-depth interviews, focusdiscussion groups, panels, consultation of voluntary groups, and analyses of complaints and surveys. However patient satisfaction survey still continues to be the most widely used mode of objectively and systematically determining cancer patient's perception of the health care received.

Individuals facing a possible diagnosis of cancer are confronted with multiple physical, psychological, and educational challenges. The patient diagnosed as having cancer has increased susceptibility to stress resulting from a positive diagnosis, its treatment, and possible prognosis. ${ }^{3,4}$ Thus cancer patients are at high risk for a variety of emotional disorders including anxiety, traumatic stress, and depression. ${ }^{3,5,6}$ The patient's stress can be amplified by long waiting room times, lack of information, 
poor communication between clinic staff and patients, and the absence of psychosocial care. ${ }^{7}$ Advances in diagnostics, treatment, supportive care and rehabilitation all necessitate continued monitoring to determine whether patients are satisfied with the increasingly complex and multidisciplinary nature of health care services that they are receiving, and to identify areas in which improvement is needed. Therefore cancer patients should be surveyed regularly due to their usual extensive and debilitating treatments that they must undergo.

Many new cancer patient questionnaires have been developed in the quest to find the perfect one. The instrument to measure patient satisfaction (the questionnaire) has to undergo reliability and validity tests ${ }^{8,9}$ before it can be used. There now are valid and reliable instruments that ask cancer patients objective questions about aspects of care that both clinicians and patients think represent quality. Newer surveys and reports can provide results that are interpretable and suggest specific areas for quality improvement efforts. ${ }^{10}$ The choice of a questionnaire depends upon the type of cancer under investigation, the availability of resources including human resources and the motives behind the collection of the data. Findings can be reported at the hospital, clinic, department or the physician level. The questionnaire can be either filled in directly by the patient or some specialized staff can help the patient complete the questionnaire.

Several questionnaires are available to measure patient satisfaction in oncology. One of the most commonly used is the European Organization for Research and Treatment of Cancer inpatient satisfaction questionnaire (EORTC QLQ-SAT32). The EORTC QLQ-SAT32 was designed to evaluate the cancer inpatient's perception of the quality of medical and nursing care, and the organization of care and services received during admission to an oncology unit. The EORTC QLQ-SAT32 comprises 32 questions divided into three subscales evaluating: (1) the medical team; (2) the nursing team; (3) organization of care and services; and includes a question evaluating general patient satisfaction. Secondly, the EORTC QLQ-SAT32 comprises a response scale providing more favorable than unfavorable options on the quality of care. ${ }^{11}$ Another commonly used questionnaire is Patient Satisfaction and Quality in Oncological Care (PASQOC). ${ }^{1,12}$ The validated PASQOC ${ }^{\circledR}$ questionnaire was developed between 1998 and 2002 in cooperation with the German Cancer Society, the KOK (Conference of Nurses in Oncology) and PICKER Institute Germany. PASQOC ${ }^{\circledR}$ relates to 13 different dimensions of patient satisfaction: (1) physician-patient relationship, (2) communication with physicians, (3) co-management and shared decision making, (4) nursing staff and other practice assistants, (5) pain and pain treatment, (6) handling of side effects, (7) involvement of family members and friends, (8) exchange with other patients, (9) practice organization, (10) additional information, (11) further support in everyday life, (12) practice environment, and (13) side-effects.

Similarly, the Long-Form Patient Satisfaction Questionnaire (PSQ-III) is a 50-item questionnaire developed to measure patient satisfaction with medical care. The PSQ-III has been validated in oncology patients in the Netherlands. It is constructed as statements of opinion, and each item has five possible responses ranging from strongly agree to strongly disagree. The items on the PSQ-III fall into one of seven multi-item subscales: general satisfaction, technical quality, interpersonal care, communication, financial aspects, time spent with provider, and access or availability or convenience. ${ }^{13}$ The Princess Margaret Hospital Satisfaction with Doctor Questionnaire (PMH-PSQ-MD) was developed and validated specifically for use in oncology patients in an outpatient setting. It presents 41 statements about physicians in the categories of information exchange, interpersonal skills, empathy, and quality of time and was validated for outpatient use with a Cronbach's alpha score of 0.97. Patients respond to statements from "strongly disagree" to "strongly agree," scored 1 to 4 . For items that elicit negative responses, scores are reversed. Each patient's score is an average of 41 equally weighted responses. ${ }^{14}$

A number of studies have assessed the distribution and determinants of patient satisfaction in oncology. These studies differ from each other with respect to the type of cancer population, cancer treatment setting, questionnaire, study design, sample size, and the outcome measures. As a result, comparing these studies against each other becomes challenging. We therefore decided to review the available literature on patient satisfaction in oncology with the following goals: summarize the results of descriptive studies that have investigated patient satisfaction with cancer care and services and identify the predictors and determinants of patient satisfaction across different oncology treatment settings.

\section{Review of studies investigating patient satisfaction in oncology} Search strategy and selection criteria

We conducted MEDLINE searches to identify epidemiologic studies on patient satisfaction in oncology. To identify 
the relevant studies, we searched using the term "patient satisfaction" in combination with the following terms: cancer, oncology, cancer care, cancer therapies, and cancer services. MEDLINE searches were also conducted using the terms "determinants", "predictors" and "factors" along with "patient satisfaction" in cancer/oncology. We also searched the bibliography of all initially selected papers to identify relevant articles that we might have missed during the primary MEDLINE search. To be included in the review, a study must have: been published in English, reported on data collected in humans with cancer, had patient satisfaction as the primary or secondary outcome measure, and had any of the following study designs (prospective, retrospective, case-control, cohort, cross-sectional, case-series, convenience sample, random sample, clinical trial, systematic review, meta-analysis). Studies using both validated as well as nonvalidated patient satisfaction surveys were included in this review. There were no restrictions according to age, gender, ethnicity, or type of and stage of cancer.

\section{Studies investigating patient satisfaction with cancer care and services}

Assessing the degrees of satisfaction in cancer patients is important to evaluate the outcome of therapy on the patient as a whole, his psychological status and overall quality of life (QoL). ${ }^{15}$ The assessment of the patients' satisfaction also provides indications for improvement of care in a particular hospital. ${ }^{16}$ Several studies have been done to study patient satisfaction in cancers like gastroesophageal, ${ }^{17}$ breast, ${ }^{18,19}$ colorectal, ${ }^{20}$ lung, ${ }^{21}$ prostate, ${ }^{21}$ and gynecological. ${ }^{6,22}$ These studies are described in Tables 1 and 2. Table 1 describes studies using a consecutive case series and random sampling designs while Table 2 describes studies using retrospective and convenience sampling designs. Within both Tables 1 and 2, the studies are arranged chronologically as per the year of publication with the most recent studies displayed on the top.

Groff and colleagues examined the effects of a newly designed outpatient oncology clinic on aspects of patient satisfaction, including satisfaction with the physical environment, wait times, continuity of care, confidentiality, and trust in providers. They concluded that patients with lung disease in the new cancer clinic were significantly more satisfied on three subscales: wait time, continuity of care, and trust in care providers, while patients with head and neck and gynecological diseases, were significantly more satisfied with wait times. In addition, patients with gynecological disease were significantly less satisfied with the physical environment over time. ${ }^{13}$ In a study by Kleeberg and colleagues, outpatient cancer patients were examined to assess their cancer care in private oncology practices and day hospitals, and to identify the extent to which staff meet the expectations of their patients. For statistical analysis, the problem frequency $(\mathrm{PF})$ was calculated for each item of PASQOC. The best results were obtained for the dimensions "further support in daily life" (3\% PF), "nurses" (5\% PF), and "physician-patient-relationship" ( $8 \% \mathrm{PF})$. Potential for improvement was most pronounced for "handling of side effects" (39\% PF), "partnership and shared decision making" (30\% PF), "side effects" (30\% PF) and "communication with other patients" (26\% PF). Considerable differences in PFs between practices were observed. ${ }^{1}$

Another study by Sherlaw-Johnson and colleagues investigated cancer patient satisfaction with care and the extent to which it varies between and within hospitals. Dissatisfaction was greater in younger, female patients. Breast cancer patients expressed least, and prostate cancer patients expressed greatest dissatisfaction. Hospital satisfaction varied by cancer type (for breast, colorectal, lung and prostate cancer patients), and with more effect on in-hospital than out-of-hospital care. Breast, colorectal and prostate cancers showed significant pair-wise correlations for standardized satisfaction scores, particularly for in-hospital care. Summed hospital satisfaction scores showed significant associations across different dimensions of care. ${ }^{21}$ Another study by Avery and colleagues examined how patient satisfaction related to surgical morbidity, treatment type, and QoL outcomes after inpatient treatment for upper gastrointestinal cancer. Patients who received palliative treatment reported satisfaction and QoL scores similar to those of patients who received curative treatment. However, patients who experienced major morbidity reported significantly worse QoL than those without morbidity. Satisfaction scores were the same in patients with or without complications. There were no associations between satisfaction and QoL scores $(\mathrm{r}<0.34)$. The study concluded that patient satisfaction with hospital care is independent of morbidity, treatment type, and QoL outcomes. ${ }^{23}$

Yet other study by Bergenmar and colleagues prospectively investigated changes in patient satisfaction at an outpatient clinic for patients with breast cancer. The questionnaire consisted of 12 multiple-choice items concerning waiting time, interpersonal skills of physician and nurse, continuity of care, length of medical visit, communication and expectations. Statistically significant improvements were found in eight of the 12 items: waiting time, length of medical 


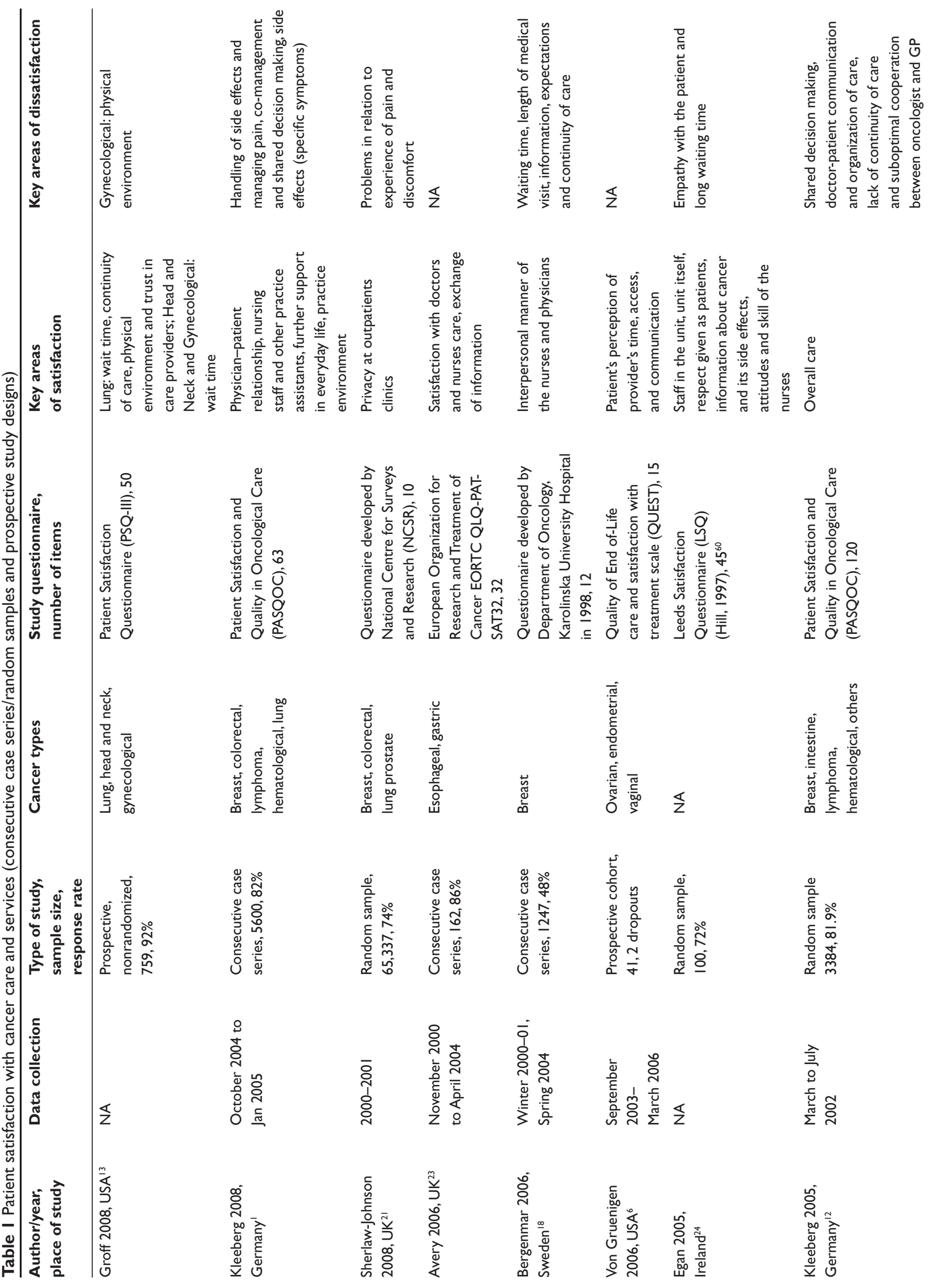



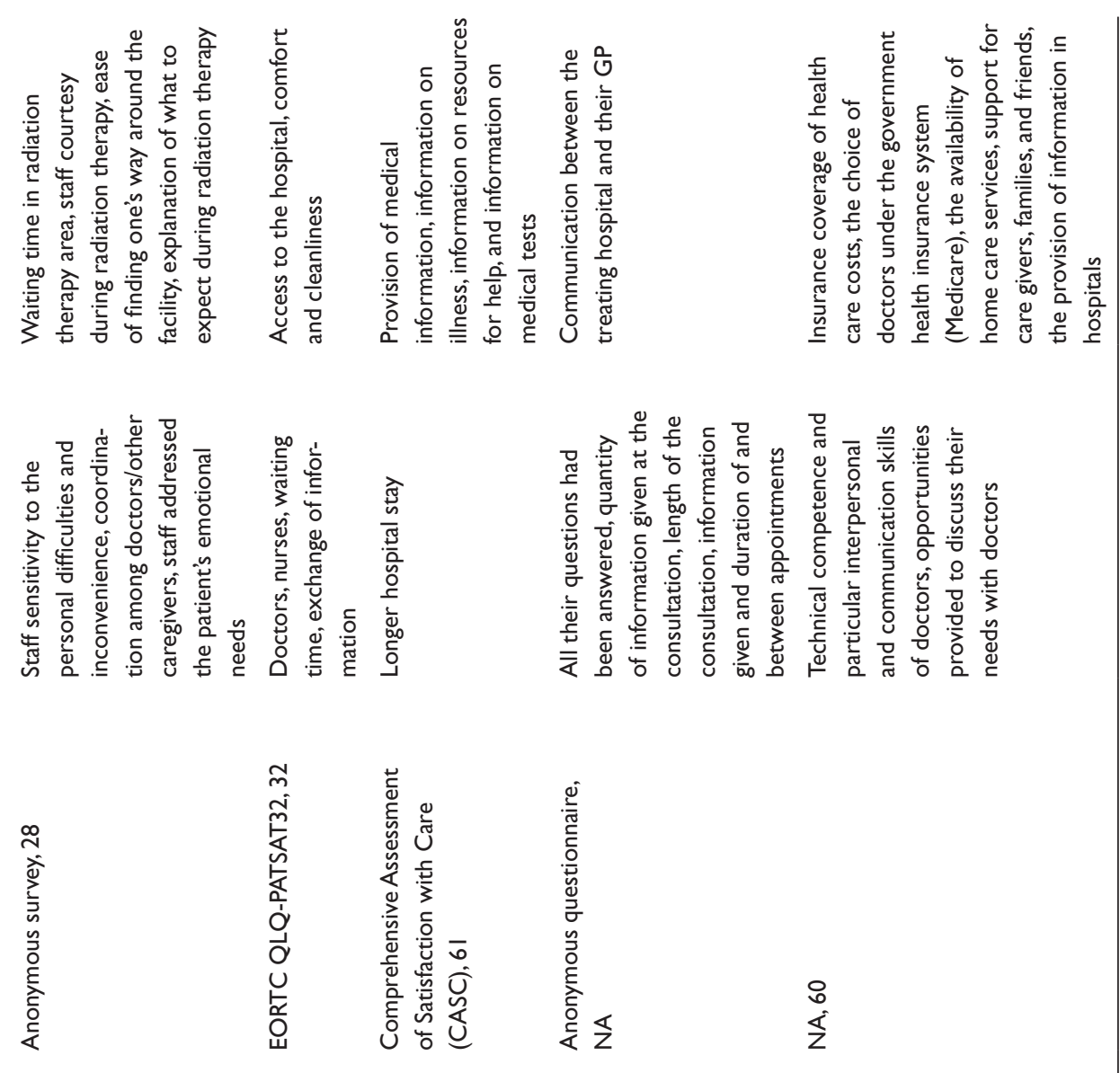

$\stackrel{8}{8}$

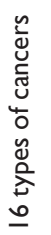
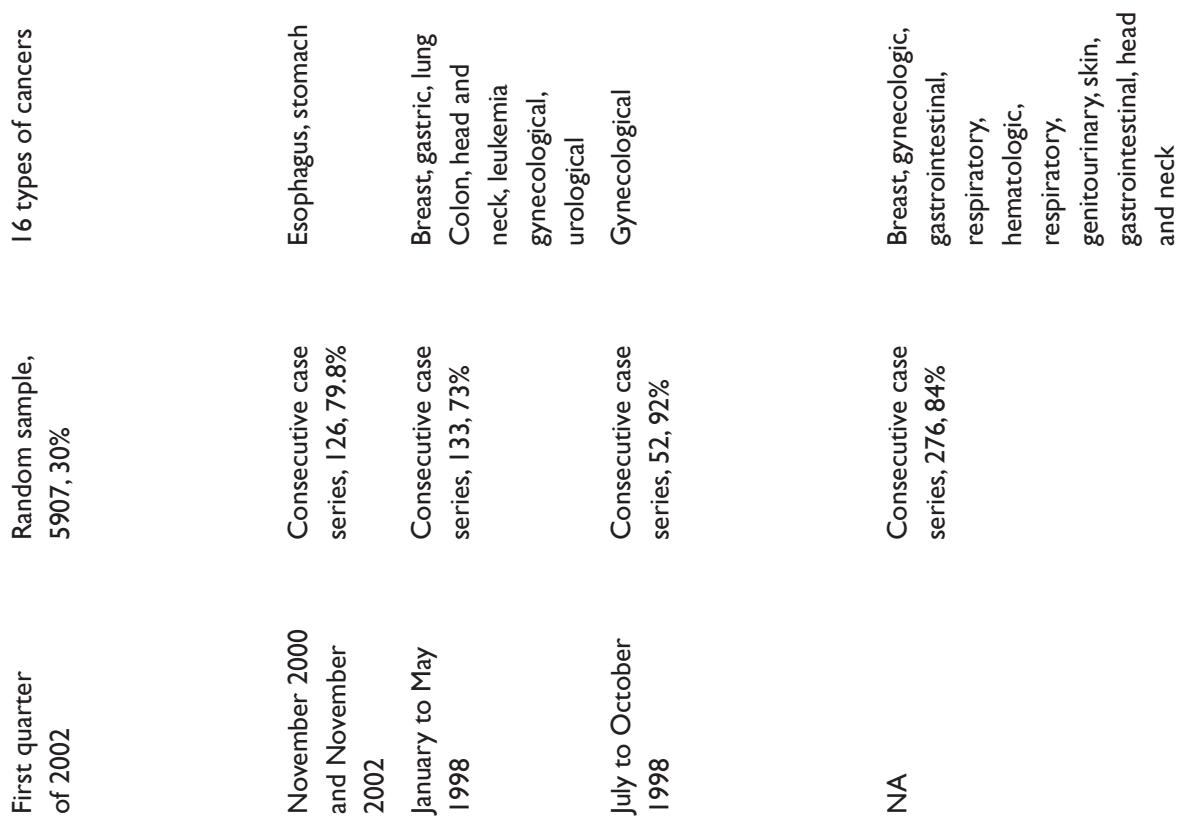

$\S$
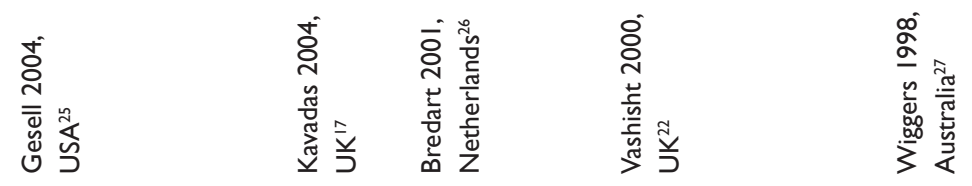


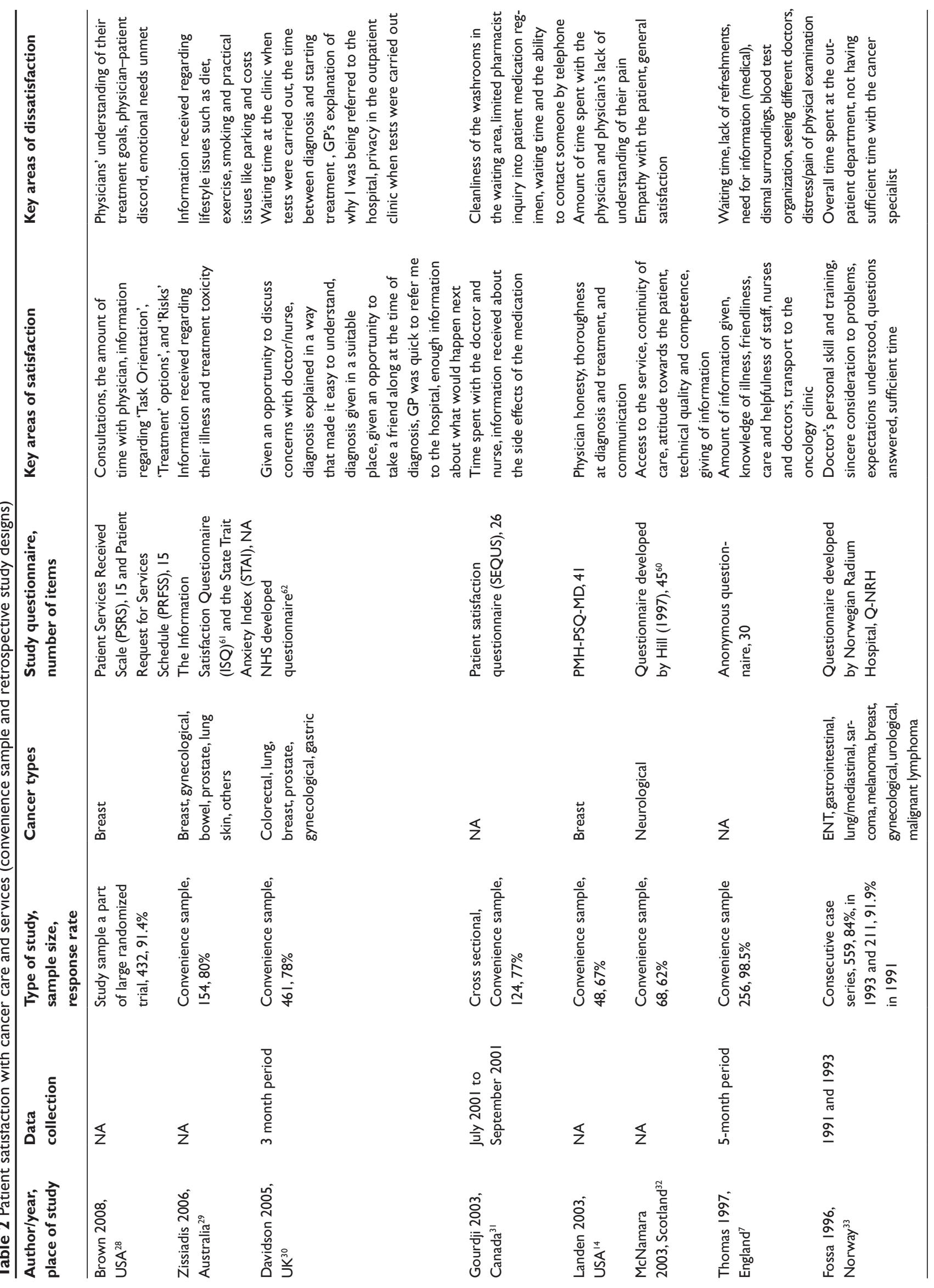


visit, information, expectations, and continuity of care. In conclusion, the questionnaire captured positive changes in patient satisfaction between the two measurements. Further changes for the better were still requested concerning continuity of care despite reported improvement. ${ }^{18}$ von Gruenigen and colleagues assessed the association between patient's satisfaction with care and symptom severity in a prospective cohort of patients with recurrent gynecologic malignancies receiving chemotherapy. Data from 39 patients were analyzed. There was no correlation between quality and satisfaction of care and symptom severity. The study concluded that patient evaluation of care may be more closely related to the interpersonal aspects of the health care provider relationship than it is to physical symptoms. ${ }^{6}$

Egan and colleagues determined the satisfaction levels of patients attending a nurse-led oncology day ward. Satisfaction levels were found to be favorable in general. Over $89 \%$ of patients were satisfied with staff in the unit and $79.4 \%$ were satisfied with the unit itself. Regarding questions relating to how the patients felt they were treated, $86.3 \%$ said they were satisfied with the unit with respect to themselves as patients. However, some patients felt they had no confidence in the person who was treating them at the time they were in the unit. ${ }^{24}$ Kleeberg and colleagues assessed the status of satisfaction with care and QoL among oncological outpatients in Germany, and identified the key factors that determine patients' willingness to recommend a medical facility. The most common cancer types were breast $(22.9 \%)$ and intestine $(19.8 \%)$. This study found that although overall satisfaction was high, there were many areas for improvement such as shared decision-making, doctor-patient communication and organization of care. QoL was significantly impaired in many domains. Patient-provider relationship, facility setting, and information on diagnosis and treatment options are major determinants of patients' willingness to recommend a facility to a friend or relative if needed. ${ }^{12}$

Data from 5,907 cancer outpatients treated at 23 hospitals across the US were analyzed by Gesell and colleagues to identify the top priorities for service improvement in outpatient cancer treatment facilities. The results suggest that the highest priorities for quality improvement involve meeting patients' emotional needs (being sensitive to the upheaval cancer causes in a person's life); providing information to family members and for self-care; reducing waiting times (wait to first visit, wait in registration, and wait in chemotherapy); providing convenience (ease of reaching office staff and ease of the registration process); and coordinating care among physicians and other care providers. ${ }^{25}$ Another study was done by Kavadas and colleagues to measure patients' satisfaction with care received for treatment of esophageal and gastric cancer, and to identify areas that contribute most to overall satisfaction scores. EORTC QLQ-SAT32 was completed following discharge. Univariable analysis showed that all dimensions of satisfaction with care contributed significantly to overall satisfaction. Multivariable analyses, however, showed that most of the variation in overall satisfaction could be attributed to levels of satisfaction with doctors, nurses, and hospital comfort and cleanliness. Overall satisfaction was not influenced equally by all aspects of care. The scores for waiting times, other hospital personnel, exchange of information, and access to the hospital did not explain the variability of the overall satisfaction score when nurses' and doctors' scores, and hospital comfort and cleanliness were included. ${ }^{17}$

Bredart and colleagues evaluated the feasibility of conducting a patient satisfaction survey in the oncology hospital setting, using a multidimensional patient satisfaction questionnaire and found that a higher global score for QoL predicted higher satisfaction with all aspects of care, and longer hospital stay predicted higher satisfaction with the different aspects of medical and nursing care. ${ }^{26}$ In another study by Vashisht and colleagues, a simple anonymous questionnaire was given to 52 consecutive patients at the gynecology oncology clinic at the Chelsea and Westminster Hospital between July and October 1998. Forty-eight questionnaires were completed. All but one patient thought the quantity of information given at the consultation was "about right", and that the length of the consultation was "about right". Five patients thought that the length of time between consultation was too long and one too short. Forty-four patients felt all their questions had been answered, the other four thought this was not the case because of time constraints, feeling intimidated by the doctor, and simply that the "doctors do not know the answers". Forty-six patients found the clinic reassuring, with only two finding it anxiety provoking. All patients requested that they either see just a hospital doctor (58\%) or a hospital doctor and Macmillan nurse $(42 \%)$. No patients requested follow-up with their general practitioner (GP). ${ }^{22}$

Wiggers and colleagues assessed the perceptions of 232 ambulatory cancer patients about the importance of and satisfaction with the following aspects of care: doctors technical competence and interpersonal and communication skills, accessibility and continuity of care, hospital and clinic care, nonmedical care, family care, and finances. The results indicate that all 60 questionnaire items used were 
considered to reflect important aspects of care, but that greater importance was given to the technical quality of medical care, the interpersonal and communication skills of doctors, and the accessibility of care. Few patients were satisfied with the provision of information concerning their disease, treatment, and symptom control and the provision of care in the home and to family and friends. ${ }^{27}$

A study by Brown and colleagues included 395 female early-stage breast cancer patients of 56 oncologists. Patients and oncologists completed a matched questionnaire measuring (a) met expectations, (b) concordance over content and item importance, and (c) satisfaction. Overall patient satisfaction was extremely high although expectations were not met at the stated level desired. Higher overall satisfaction was predicted by levels of met expectations and concordance over (a) content and (b) importance. ${ }^{28}$ A survey was undertaken by Zissiadis and colleagues to ascertain the current level of patient satisfaction with the information they were receiving from their treating radiation oncologist. Two questionnaires were given to patients having radical radiotherapy for malignancy. The first questionnaire consisted of the Information Satisfaction Questionnaire and the State Trait Anxiety Index. It was given to patients before the commencement of their course of radiotherapy. The second questionnaire consisted of the State Trait Anxiety Index and was given at the completion of their radiotherapy. The majority of patients were satisfied/very satisfied with the explanation of their illness and radiation toxicities. Fewer patients were satisfied with the explanation of lifestyle (eg, diet, exercise, smoking) and practical issues such as parking and treatment costs. ${ }^{29}$

Davidson and colleagues examined 435 cancer patients throughout Northern Ireland during a three-month period. While overall satisfaction scores were relatively high, there was considerable variation. The interaction between perceived satisfaction and quality of care, communication, tumor site, and age was significant. The relationship between gender, age, and perception of care during early illness was examined. The younger patients $(<45$ years) were significantly less satisfied with communication of diagnosis than the older patients. The younger patients were also significantly less satisfied with the privacy in the outpatient clinic when the tests were carried out and the time it took for the diagnosis to be reached. Those patients with high incidence tumors, that is, breast, lung and colorectal reported significantly higher satisfaction than patients suffering from 'other cancers', that is, prostate, gynecological and gastric cancers. ${ }^{30}$
A convenience sample of 96 patients recruited by Gourdji and colleagues from an oncology outpatient center completed a 26-item patient satisfaction questionnaire (SEQUS). Satisfaction rates ranged from $47 \%$ to $79 \%$, and importance ratings ranged from $89 \%$ to $99 \%$, with higher percentages indicating greater satisfaction and level of importance. Patients' perception of waiting time and lack of questioning regarding their medications by the pharmacist were identified as two areas needing improvement. Findings suggest that by identifying what is most important to patients, nurses can readily modify the care environment to enhance patient satisfaction and quality of care. ${ }^{31}$

A study was performed by Landen and colleagues to examine the satisfaction of a specific population of oncology patients with their physicians and to quantify its association with characteristics of their disease. Patients reported a desire for more time with physicians and that their pain be better understood. Patients were most satisfied with the physician's honesty, thoroughness, and communication. Satisfaction scores did not correlate with intensity of treatment or time since diagnosis. Patients were generally satisfied with their physicians, regardless of treatment intensity. Patients with the heaviest financial burden were significantly less satisfied than those with a minimal or moderate burden. ${ }^{14} \mathrm{McNamara}$ and colleagues investigated whether the neuro-oncology team was meeting the aims of providing the patients with proper care. Sixty-eight patients returning to the neurooncology clinic for routine follow-up were asked to complete a patient satisfaction questionnaire. All the patients were selected on the basis that they had attended the clinic previously and had a diagnosis of intracerebral tumor. General satisfaction accounted for the highest levels of dissatisfaction $(10 \%, n=7)$; however, it also scored the highest levels of satisfaction for $20 \%$ patients $(n=14)$. Only one patient was dissatisfied with the delivery of information. Empathy with the patient was another area in the results which indicated dissatisfaction for $9 \%(n=6)$ of patients. ${ }^{32}$

A survey by Thomas and colleagues of 252 oncology patients investigated patients' satisfaction with the clinic, anxiety associated with clinic attendance, and the strengths and weaknesses of the oncology service. Far from being perceived as anxiety-provoking, the clinic was looked upon as a valuable source of reassurance, $92 \%$ of patients reporting they were 'always' or 'usually' reassured as a consequence of their visit. Qualitative data showed that clinic staff was the most important source of satisfaction. Waiting was overwhelmingly the worst aspect of the clinic, described by $27 \%$ of patients as 'excessively long'. One-fifth of the total 
sample had attended the clinic for 10 years or more and over a third of this group reported they would be worried at the prospect of being discharged to the care of their GPs. Despite disadvantages associated with long waits, the clinic was perceived as providing a valuable source of reassurance which a proportion of patients were clearly reluctant to be without. ${ }^{7}$ Fossa and colleagues described the cancer patients visiting the out-patient clinic at the Norwegian Radium Hospital (NRH) with regard to their physical status and evaluated the patients' satisfaction with the out-patient service. Consecutive patients were asked by an introducing letter to complete two questionnaires: the EORTC QLQ-C30 and a questionnaire designed specifically for the purpose of the present investigation: Q-NRH. There was no association between the patient's satisfaction and age, gender, history or status of the disease or whether he/she currently received treatment for the malignancy. Only 20\%-25\% of the patients felt thoroughly informed about their malignancy, its treatment, and possible side effects. Patients who judged themselves as well informed were significantly more often satisfied with the consultation than those who lacked sufficient knowledge about their malignancy. ${ }^{33}$

Ishikawa and colleagues described characteristics of physician-patient communication in a Japanese cancer consultation and examined the relation of this interaction with patient satisfaction. One hundred forty cancer outpatients and 12 physicians were included. The Roter Interaction Analysis System (RIAS), one of the most frequently used systems for analyzing physician-patient interaction, was applied. Patients were more satisfied with consultations in which the physician used more open-ended questions. On the other hand, physician direction and encouragement was negatively associated with patient satisfaction. Patients who asked more questions were less satisfied with the consultation. ${ }^{34}$ Quinn and colleagues described how a multidisciplinary hospital responded to patient-satisfaction issues and improved communication throughout its organization by implementing a real-time assessment of patient and staff satisfaction for a faster and better-focused improvement process. The survey process was based on eliciting information from several different sources in a manner that allowed corrective action plans to be made and implemented within four to eight weeks of patient encounters. Organized groups then reviewed feedback from the implemented action plans within nine to 16 weeks of patient encounters. The program has become a model for goal-setting and establishing management accountability. As an adaptation of continuous quality improvement, the Real-Time Patient Satisfaction Survey and Improvement
Process at the Moffitt Cancer Center are applicable for use in other hospitals and cancer centers in the United States. ${ }^{35}$

A randomized, controlled trial by Isenring and colleagues investigated the impact of nutrition intervention (NI) vs usual care (UC) in 54 ambulatory oncology patients receiving radiotherapy to the gastrointestinal or head and neck area reported that changes in patient satisfaction were associated with improved outcomes for patients receiving NI compared with UC. Patients receiving NI rated satisfaction higher for staff interpersonal skills, perceived health benefits $(\mathrm{P}=0.008)$, staff presentation skills and for overall patient satisfaction with nutrition services. ${ }^{36}$

Koinberg and colleagues investigated a strategic sample of 20 women with breast cancer, routinely followed-up at an oncology outpatient clinic. A qualitative descriptive design was used. The women's views demonstrated that there are strong reasons for reviewing and changing the design of the traditional follow-up system to obtain the most effective and well-functioning system possible to better meet these women's needs. The results identified six categories describing women's needs and satisfaction with routine follow-up visits to the physician after surgery for breast cancer: routine, accessibility, security, continuity, confidence, and individualized information. ${ }^{37}$

Gallant and colleagues evaluated a new-patient orientation program in a cancer center in 213 participants. The program was designed to: (1) provide patients with information about the center's facilities and procedures, (2) give them an opportunity to ask questions and discuss personal concerns, (3) provide them with detailed information concerning support services available in both the community and the cancer center, and (4) provide them with access to a support care practitioner for follow-up contact. The results showed that participants were extremely satisfied with the program, it helped them deal more effectively with their first visit to the center, and it increased their feelings of relaxation and comfort and reduced their feelings of fear and anxiety. These results support the use of informational and support interventions as an effective means of improving cancer care. ${ }^{38}$ Bredart and colleagues reported a cross-cultural comparison of the comprehensive assessment of satisfaction with care (CASC) response scales. The authors investigated what proportion of patients wanted care improvement for the same level of satisfaction across samples from oncology settings in France, Italy, Poland, and Sweden, and whether age, gender, education level, and type of items affected the relationships found. One hundred and forty, 395, 186, and 133 consecutive patients were approached in oncology settings from France, Italy, Poland, and Sweden, 
respectively. They found that an increasing percentage of patients wanted care improvement for decreasing levels of satisfaction. However, in France a higher percentage of patients wanted care improvement for high-satisfaction ratings whereas in Poland a lower percentage of patients wanted care improvement for low-satisfaction ratings. ${ }^{39}$

To improve the provision of information to their radiotherapy patients, D' haese and colleagues examined whether the timing of given written information had an effect on anxiety and satisfaction. Two sources of information were used: 1) a booklet with a description of radiotherapy procedures and the sensations patients can experience; 2) teaching sheets with treatment-site-related information. Sixty-eight patients were randomized to a simultaneous-information group $(n=31)$ and a stepwise-information group $(n=37)$. The study found that the stepwise-information group was significantly less anxious before simulation and more satisfied. Of the variables studied, only the support variable was associated with high state anxiety. It was concluded that provision of patient information in a stepwise format leads to less treatment-related anxiety and greater patient satisfaction among radiation therapy patients undergoing simulation. ${ }^{40}$ Grunfeld and colleagues assessed the effect on patient satisfaction of transferring primary responsibility for follow-up of women with breast cancer in remission from hospital outpatient clinics to general practice. Two hundred and ninety-six women with breast cancer in remission receiving regular follow-up care at two district general hospitals in England were included in the study. Patient satisfaction was measured by means of a self-administered questionnaire supplied three times during the 18-month study period. It was found that the general practice group selected responses indicating greater satisfaction than did the hospital group on virtually every question. Furthermore, in the general practice group there was a significant increase in satisfaction over baseline. Hence it was concluded that patients with breast cancer were more satisfied with follow-up in general practice than in hospital outpatient departments. When discussing follow-up with breast cancer patients, they should be provided with complete and accurate information about the goals, expectations, and limitations of the follow-up program so that they can make an informed choice. ${ }^{41}$

\section{Studies investigating predictors of patient satisfaction in oncology}

A number of studies have been conducted to evaluate predictors of patient satisfaction in oncology. These studies are described in Tables 3 and 4. Table 3 describes studies using a consecutive case series and random sampling designs while Table 4 describes studies using retrospective and convenience sampling designs. Within both Tables 3 and 4, the studies are arranged chronologically with the most recent studies displayed on the top.

Sandoval and colleagues outlined predictors of cancer patients' overall perceptions of the quality of care. During September and October 2004, the Ambulatory Oncology Patient Satisfaction Survey (AOPSS) was mailed to 8,521 cancer patients who had visited 15 comprehensive cancer care programs across Ontario, Canada. A total of 5,015 surveys were returned out of which only 2,790 patients were evaluable. The authors found that patients perceived following predictors as relatively problematic aspects of care. These are 'was informed about follow-up care after completing treatment', 'knew next step in care', 'knew who to go to with questions', and 'providers were aware of test results'. Patients' age, gender, type of cancer, self-assessed health, and who completed the survey were the variables adjusted. These predictors explained between $25 \%$ and $34 \%$ of the variance of the overall perception of quality. The explanatory power of these predictors did not change across gender and age group. ${ }^{42}$ Predictors of 'patient satisfaction' with hospitalization at a specialized cancer hospital in Norway were examined in a study by Skarstein and colleagues. Two weeks after their last hospitalization, 2,021 consecutive cancer patients were invited to rate their satisfaction with hospitalization, QoL, anxiety, and depression. Compliance rate was $72 \%(n=1453)$. Cutoff levels separating dissatisfied from satisfied patients were defined. It was found that $92 \%$ of the patients were satisfied with their stay in hospital, independent of cancer type and number of previous admissions. Performance of nurses and physicians, level of information perceived, outcome of health status, reception at the hospital, and anxiety independently predicted 'patient satisfaction'. ${ }^{16}$

Haggmark and colleagues assessed the efficacy of various information outputs on 210 consecutive cancer patients. Patients were randomized into three groups before the start of curative radiation treatment: 1) standard information plus group and repeated individual information, 2) standard information plus brochure, and 3) standard information only. Patients receiving standard information plus group and repeated individual information were significantly more satisfied with the information than were patients in the remaining two groups. ${ }^{43}$ Ong and colleagues studied the relationship between (a) doctors' and patients' communications and (b) doctors' patient-centeredness 


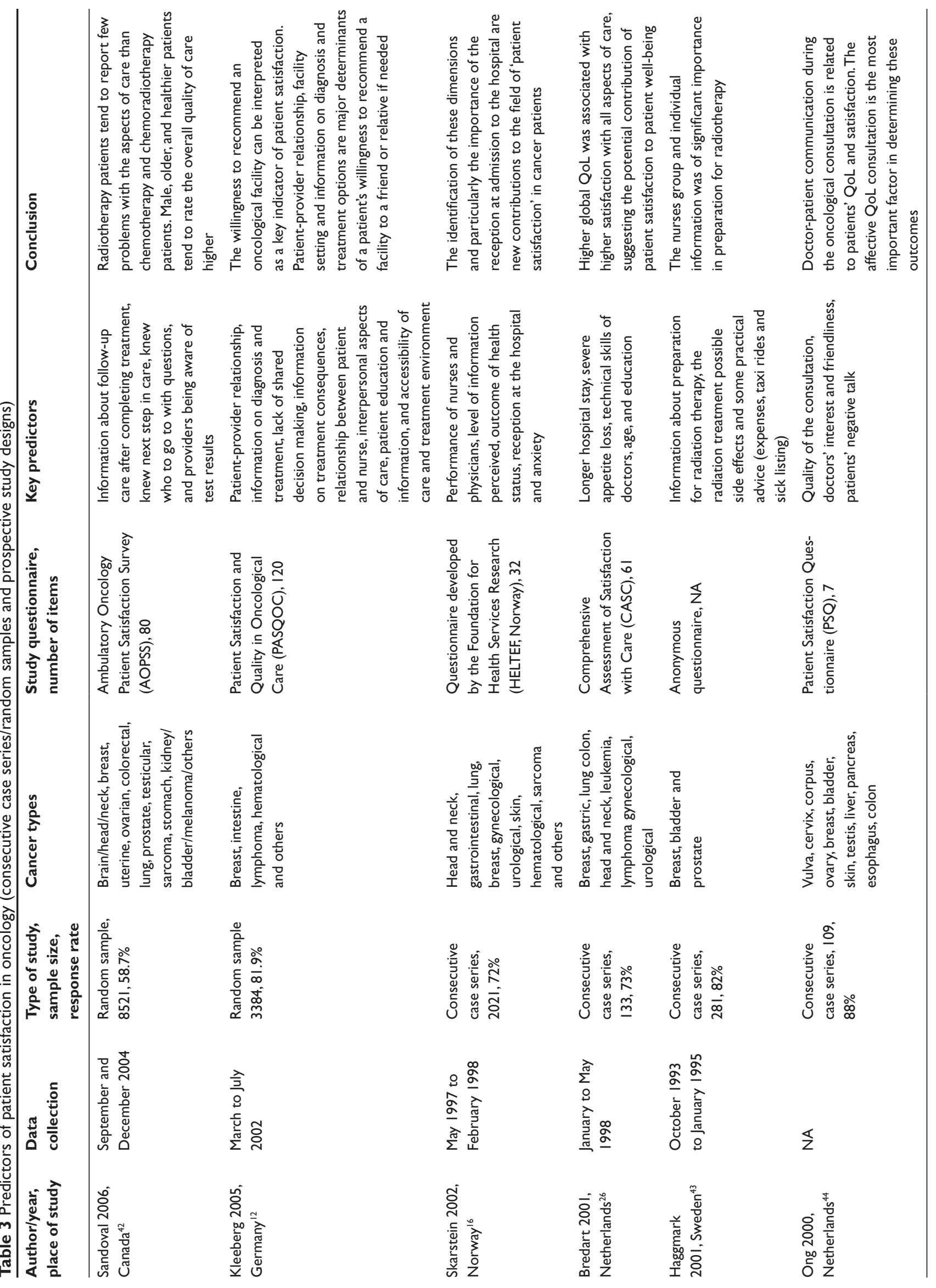




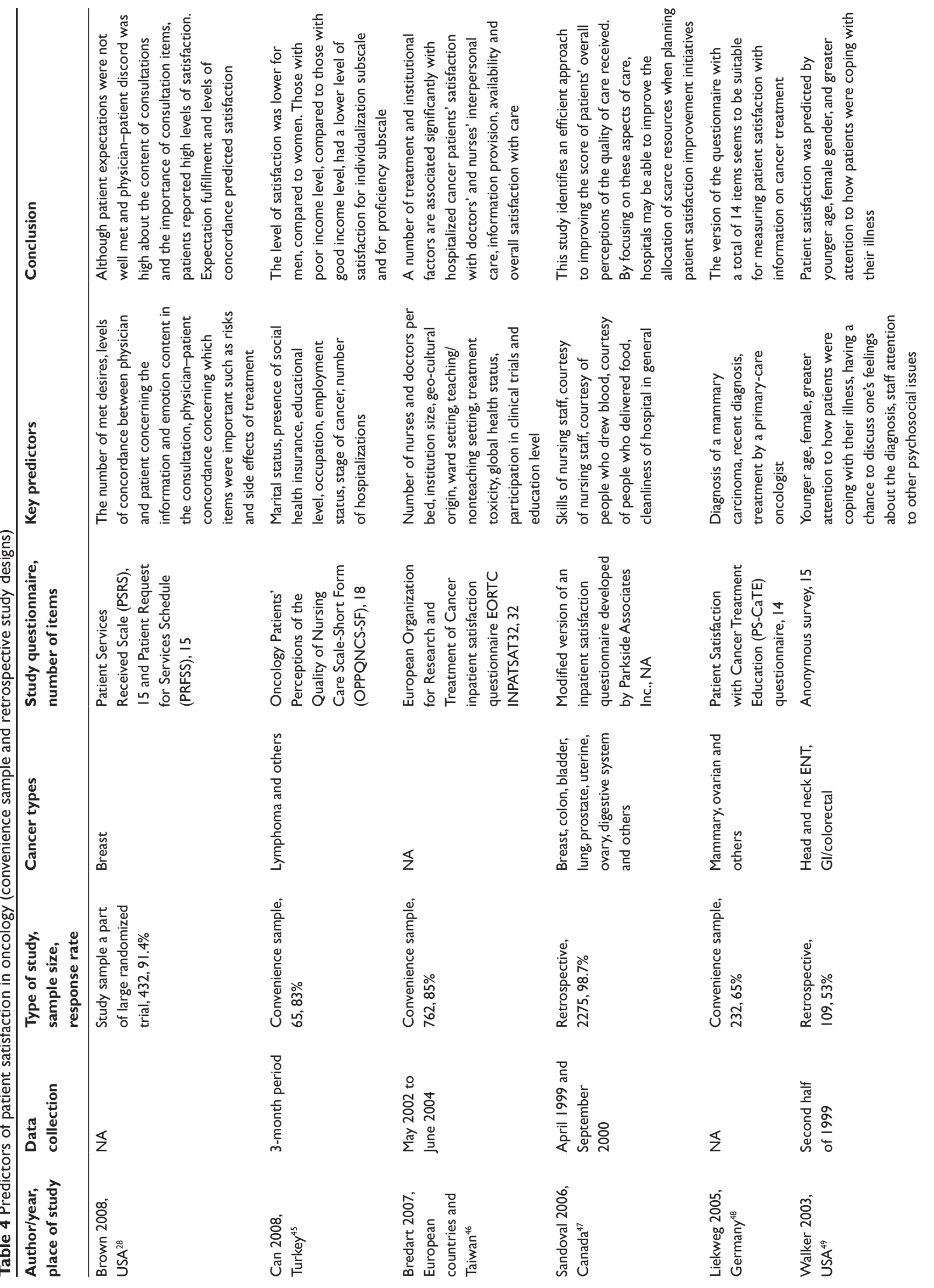



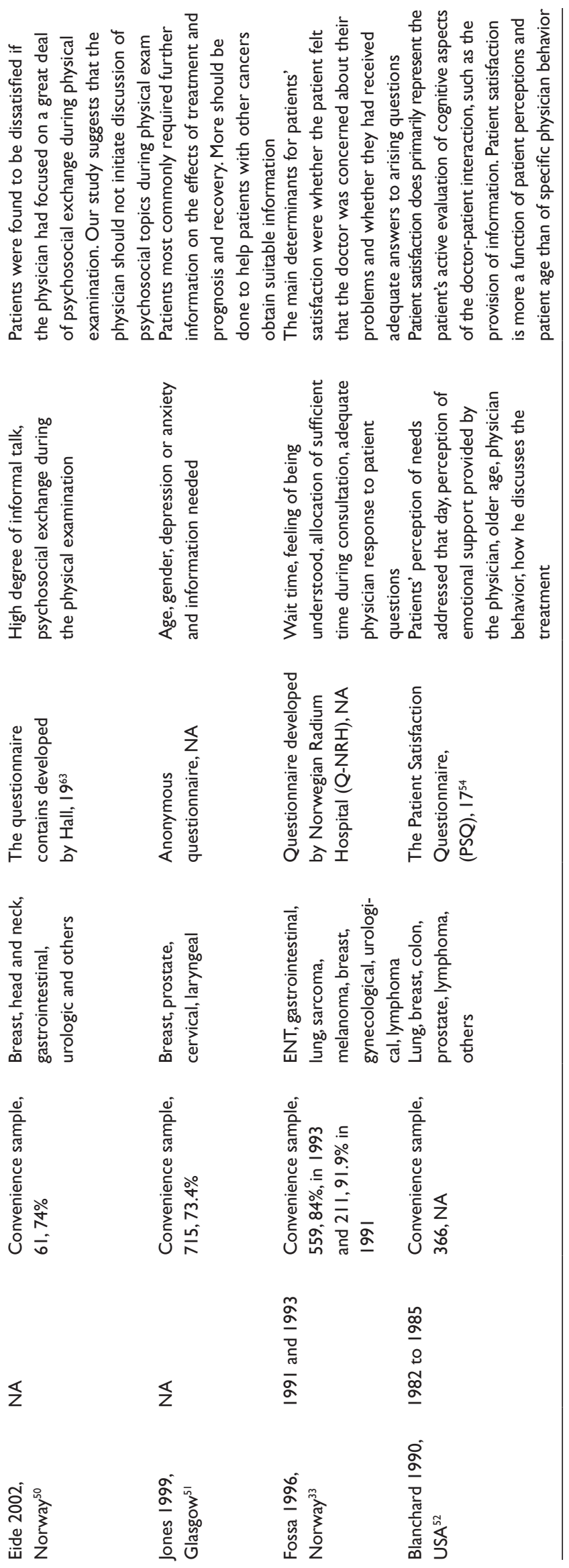

during the oncological consultation and patients' QoL and satisfaction was examined. Consultations of 96 consecutive cancer patients were recorded and content analyzed by means of the RIAS. Multiple regression analyses showed that patients' QoL and satisfaction were most clearly predicted by the affective quality of the consultation. The oncologists' patient-centeredness was negatively related to patients' global satisfaction after three months. ${ }^{44}$

Brown and colleagues evaluated patient satisfaction by examining expectations of a sample of breast cancer patients and concordance with their medical oncologists about the content of consultations and the importance of consultation items. Three hundred ninety-five female early stage breast cancer patients of 56 oncologists participated. Patients and oncologists completed a matched questionnaire measuring (a) met expectations, (b) concordance over content and item importance, and (c) satisfaction. Higher overall satisfaction was predicted by levels of met expectations and concordance over content and importance. Expectation fulfillment and levels of concordance predicted satisfaction. Overall patient satisfaction with the consultation was equivalent regardless of age, education, marital status, and ethnicity. ${ }^{28}$ Can and colleagues tested whether the Turkish version of the Oncology Patients' Perceptions of the Quality of Nursing Care Scale-Short Form (OPPQNCS-SF) is appropriate for oncology patients by studying the tool's validity and reliability and to evaluate the effect of care given by nursing students on oncology patients' satisfaction with the care they receive. The results showed that the scale is a valid and reliable tool for Turkish patients. The patients were most pleased about the respect they were shown, with the answers to their questions, with the sincere interest shown and with the knowledge of nurses about their condition. ${ }^{45}$

Bredart and colleagues found that patients with a higher than compulsory education level or with a lower than a university education level reported lower overall satisfaction; patients reporting lower overall satisfaction were treated in a medical ward and had major compared to minor treatment toxicity; patients treated in a clinical trial were less satisfied with doctors' interpersonal skills than patients who were not; patients with a relatively higher level of global health status reported higher level of satisfaction with doctors' and nurses' interpersonal skills, information provision and availability, and of satisfaction with care overall; patients treated in nonacademic settings reported higher overall satisfaction compared to patients treated in academic/teaching settings; patients were less satisfied with doctors' availability and more satisfied with nurses' information provision in settings 
composed of more nurses per bed; patients were less satisfied with nurses' interpersonal skills and availability, and less satisfied with the care overall in institutions of larger size and with a higher number of doctors per bed. ${ }^{46}$ Sandoval and colleagues identified aspects of care that can most easily be modified to produce an improvement in the score of patients' overall evaluations of the quality of care received. The sample consisted of 2,247 cancer patients hospitalized in Ontario acute care hospitals in 1999/2000. Two main subgroups were analyzed in this study: patients with malignant and benign neoplasms. 'Skills of nursing staff', 'courtesy of nursing staff', 'courtesy of people who drew blood' and 'cleanliness of hospital in general' were consistently found to be predictors of overall care. Patients hospitalized once during the past two years evaluated significantly higher the quality of care than those hospitalized three and four times. It was also found that less healthy cancer patients (selfassessed health) tended to judge the quality of care lower than healthier cancer patients. ${ }^{47}$

A survey was done in Germany by Liekweg and colleagues to measure patient satisfaction with information on cancer treatment. Since there was no suitable German measure available, the Canadian Patient Satisfaction with Cancer Treatment Education (PS-CaTE) questionnaire was translated into German and its test quality criteria were examined. Selected sociodemographic variables were added to the original version of the questionnaire to facilitate subgroup analysis. A stepwise multiple-regression analysis identified three significant predictors of satisfaction: a) diagnosis of a mammary carcinoma; b) recent diagnosis; and c) treatment by a primary-care oncologist. Patients with a mammary carcinoma and patients treated by a primary-care oncologist were less satisfied, and patients with a recent diagnosis were more satisfied compared to other patients. ${ }^{48}$ Walker and colleagues examined patient satisfaction with treatment-planning and follow-up appointments among 58 ear-nose-throat and gastrointestinal cancer patients seen at a multidisciplinary cancer clinic. Overall satisfaction was predicted by younger age, female gender, and greater attention to how patients were coping with their illness. Having a chance to discuss one's feelings about the diagnosis, and staff attention to other psychosocial issues, also predicted patient satisfaction. Results suggested that patient satisfaction may be enhanced when hospital staff attend to and provide for the psychosocial needs engendered by a diagnosis of cancer. ${ }^{49}$

Eide and colleagues identified the relationship between content during the different phases of the consultation and overall patient satisfaction with regular follow-up consultations at a cancer outpatient clinic. Thirty-six consultations were analyzed with RIAS. The regular follow-up consultations were rather short aiming at discussing medical and therapeutic aspects of the illness. There was a positive correlation between physician informal talk and patient satisfaction in the history-taking phase. Patients were found to be dissatisfied if the physician had focused on a great deal of psychosocial exchange during physical examination. ${ }^{50}$ Jones and colleagues surveyed the views of cancer patients entering a randomized trial of computer-based information. The authors examined cancer patients' need for information and their satisfaction with information received and how these varied with their demographic, social, and psychological characteristics. Information need (as much as possible) was considered both as a response variable and as a predictor of sources and satisfaction. Patients with breast cancer had received more information and from more people than patients with other cancers but were not significantly more likely to be satisfied. Younger depressed patients who wanted as much information as possible were less likely to be satisfied even though they had received more information than others. ${ }^{51}$

To examine potential predictors of cancer patient satisfaction with physician behavior, 366 cases were studied by Blanchard and colleagues. Results showed wide variation in physician behavior; no standard set of behaviors was seen in all interactions. The strongest predictor of patient satisfaction was the patient perception item, perception of needs addressed that day. Other predictors were perception of emotional support provided by the physician, age (older), and one physician behavior, discusses treatment. Patient perceptions of needs met or emotional support provided were predicted by perceptions of the occurrence of physician behaviors involving information such as the diagnosis and tests and treatment. Overall, patient perceptions of physician behaviors were stronger predictors of patient satisfaction than the actual occurrence or absence of those behaviors. $^{52}$

Bitar and colleagues investigated whether tumor status influences patient satisfaction with interaction with their doctors. Outpatients attending clinics at a major cancer center completed a battery of questionnaires, including the Patient Satisfaction with Doctor (PSQ-MD) questionnaire, a 24-item, self-report instrument. Data concerning tumor status and satisfaction were obtained for 569 patients, sampled to include equivalent numbers of women and men with breast, head and neck, gastrointestinal, genitourinary, or lung cancer, or lymphoma. Controlling for age, marital status, annual family income, stressful life events, and employment status, 
patients with metastatic disease felt somewhat less supported by their physicians than those with localized disease. These findings were consistent across cancer diagnoses. Patients with metastatic disease may feel less physician support than those with less advanced cancers. ${ }^{53}$

To determine the impact of specific physician behaviors on patient satisfaction, Blanchard and colleagues examined 401 individual interactions using a previously developed physician behavior check list and several visual analog scales that assessed patient satisfaction. Patient satisfaction for the entire group was high and failed to correlate significantly with specific physician behaviors. For the high satisfaction group older age, a poorer prognosis, and a positive quality of the day's news were associated with higher satisfaction. Use of the patient's first name and attempts to establish privacy during an exam were positively correlated with satisfaction, whereas discussing the role of the family had a negative impact. For the lower satisfaction group, a series of routine social skills behaviors (eg, sitting while talking to patients, not interrupting) and two medically related behaviors correlated best with patient satisfaction. There was little significant impact on satisfaction of behaviors related to the provision of either medical information or emotional support. ${ }^{54}$

Many studies have assessed the effectiveness of different approaches aimed at improving doctor-patient communication in oncology. These interventions focus on patients, such as handing out of videos or written preparatory information; on doctors, such as patients' self-rating feedback to doctors or communication skills trainings; or on both, such as the audiotaping of the consultation or the provision of decision aids. Bredart and colleagues considered the effects of such initiatives on patient satisfaction, with a focus on reports published since January 2004 and found that such initiatives have a positive effect on patient satisfaction. They further established that these initiatives should target both doctors and patients. ${ }^{55}$

Jansen and colleagues assessed (1) whether early-stage breast cancer patients perceived that they had treatment choice with regard to adjuvant chemotherapy, (2) what reasons patients provide for their perception of having had no choice of treatment, and (3) whether the perception of treatment choice is related to satisfaction with the assigned treatment, experienced chemotherapy burden and current QoL. A total of 448 patients, treated between 1998 and 2003, filled in the questionnaire. Of the 405 patients who had answered the question on treatment choice, 316 patients (78\%) had perceived no choice. The most frequently indicated reason for lack of choice was: 'I follow the doctor's advice.'
The authors found no differences in the levels of satisfaction with assigned treatments. However, they found an interaction effect, which indicated that the impact of perception of treatment choice on QoL was dependent upon whether the patient had been treated with chemotherapy or not. The study concluded that in cases when the decision to be treated or not has potential consequences for the chance of survival, patients' QoL may not be improved by the perception of having had a choice of treatment. ${ }^{56}$

Feyer and colleagues examined the frequency of side effects and fatigue in ambulatory cancer patients and analyzed how these symptoms are reflected in patient satisfaction. Private practices $(\mathrm{N}=41)$ and day hospitals $(\mathrm{N}=8)$ in Germany took part in the study. The respondents were 4,538 patients with cancer (response rate: $82 \%$ ). The diagnoses were: $25 \%$ breast cancer, $21 \%$ colorectal cancer, $11 \%$ lymphomas and $12 \%$ hematological malignancies. The most frequent single side effects were fatigue (60\%), hair loss (54\%), nausea (51\%), sleep disturbance (42\%), weight loss $(36 \%)$, diarrhea (32\%), and mouth ulcerations (31\%). Both the total number of side effects and the fatigue score were negatively associated with patient satisfaction. It was concluded that side effects and especially fatigue are frequent problems in cancer patients and are related to the patients' assessment of cancer care. ${ }^{15}$

The purpose of a study by Poroch and colleagues was to test the effectiveness of preparatory patient education in reducing anxiety and improving satisfaction during the course of treatment. A quasiexperimental time series design was used to compare two groups of 25 patients, matched according to treatment type and gender, commencing radiation therapy for the first time. The experimental group received two structured teaching interventions incorporating sensory and procedural information designed to familiarize the patient with the forthcoming experience. The control group received the standard information. The results indicated that the experimental group was significantly less anxious and more satisfied during radiation therapy than their counterparts in the control group, and the effects were maintained throughout the treatment period of up to seven weeks. ${ }^{57}$

\section{Discussion}

Hospitals and other health care centers use patient satisfaction information while making important decisions regarding the operational and treatment plans. ${ }^{58}$ The health centers can also use patient satisfaction results to design and track quality improvement over time, as well as compare themselves to other health centers. Also this information is of great use for 
accreditations. By conducting their own surveys, the health care organizations are able to recognize and resolve potential patient satisfaction problems and thus improve their strategies. ${ }^{18,59}$ Having satisfaction surveys also helps identify the specific needs of the patients for the health care provider. ${ }^{27}$

Patient satisfaction in oncology patients has been the focus of numerous studies, but these investigations differ on so many dimensions, especially the questionnaire used to assess satisfaction, that generalizing from the existing findings is somewhat problematic. Some potential confounders of satisfaction include type of cancer, stage, type of treatment, patient demographics, type of study sample, institutional setting, and location. Most critically, a diversity of questionnaires have been used as a consequence of a wide variety of specific questions to assess satisfaction. Very few studies ask about all aspects of satisfaction, except perhaps those that have used the validated EORTC QLQ-SAT32 and PASQOC instruments. This means that one must be cautious in comparing studies, and it is necessary to focus on areas of agreement more than disagreement.

Two studies used the EORTC QLQ-SAT32, and they both found that key areas of satisfaction were with doctors, nurses, and the exchange of information. ${ }^{17,23}$ They did not agree on areas of dissatisfaction. Two studies used the PASQOC, and they agreed only in part on areas of dissatisfaction (shared decision making). ${ }^{1,12}$ These studies used similar populations and the two studies using the PASQOC were done by the same investigator. Confusingly, patients express both satisfaction and dissatisfaction with the same aspects of care, treatment, or ancillary services, such as interpersonal skills of physicians or information supplied on treatment. Some areas are mentioned in a large fraction of the studies, others hardly at all. Since the quality of care can vary for a variety of reasons, and hence satisfaction, the key findings from existing studies are the areas in which patients more often express satisfaction or dissatisfaction.

A majority of studies found that satisfaction with the information provided by medical staff about a patient's illness and the course of treatment is important. This is followed closely by the time spent with the physician and the interpersonal skills of the physician. Other key factors are waiting time to get an appointment, empathy of staff with the patient, the continuity of care provided, and satisfaction with the nursing staff. From these results, we can conclude that 1) patients want full and complete information about their disease and its treatment, 2) they wish to be treated with respect and empathy, and 3) they would prefer that waiting times be reasonably short. There are other areas of satisfaction as well that are listed in more than one study, including the management of pain and side effects, and the continuity of care. Patients are unlikely to express complete satisfaction with a provider or institution unless almost they are very satisfied with almost all areas of their care, but the most important areas can be identified from these studies. Future studies should concentrate on making their results more comparable to past studies. This can be accomplished best by using validated questionnaires, or, if not, comprehensive questionnaires that ask about a wide range of areas of care and treatment. Most important is using questions to measure satisfaction that have been used in other studies, including exact wording and response options. Otherwise, comparability becomes difficult to achieve.

Studies that have assessed which factors influence, or predict, patient satisfaction, have been as varied as those that have measured the extent and dimensions of patient satisfaction. Only tentative generalizations are possible across these studies because they have had diverse research designs and varied on many attributes. Most importantly, the studies have not been consistent in what factors were included in models to predict patient satisfaction.

The relationships between ratings of patient care and service and patient satisfaction are uniformly positive. As ratings increase, so does patient satisfaction. It is not possible to determine the effect size for various predictors of patient satisfaction; instead, we can summarize which factors appear most often as significant predictors. Additionally, several studies controlled for patient condition, such as type of treatment or health status,,$^{12,43,45,46}$ and several included controls for patient demographics, including age, gender, and education. ${ }^{26,45,49,51}$ For the most part, those factors which are significant predictors of patient satisfaction are closely related to patient care. They include nurses' performance, physicians' performance, physician attitude toward the patient (eg, considerate, providing emotional support), and the information provided to a patient about her condition and treatment program. Patients are usually not in a position to reliably judge the soundness of a diagnosis or treatment plan, but they can judge whether they have been provided with sufficient information, and they can judge the demeanor and attitudes of their physicians. Reassuringly, these latter factors are under the direct control of medical staff, which makes it possible for patient satisfaction to be improved with appropriate efforts.

There is no consistent relationship between patient health status and satisfaction. Studies do not ask about satisfaction only among patients who have been treated and are in remission, although one would expect that above and beyond 
other factors, being in remission would increase satisfaction. However, patient satisfaction must be managed throughout the treatment process, and especially for that group of patients whose diagnosis is poor. For this reason, the outcome of treatment and its effect on satisfaction have not been studied. There is little consistency in the effect of demographic factors. For example, sometimes age is positively related to satisfaction, but in other studies it has a negative relationship. If there is any regularity in the relationship of a specific demographic factor to satisfaction, it will take more research to uncover it, and any relationship will likely be conditioned on other factors. An area little explored is how institutional setting, including type of hospital (such as teaching, community), ratio of staff to number of beds, and location (urban versus suburban) affects patient satisfaction.

There are several fruitful areas for future research. Studies should comprehensively measure patient demographics, clinical condition, and treatment programs so this information can be used as controls in models predicting satisfaction. Because patient satisfaction is linked to the behavior of physicians and other primary health care providers, it would be very helpful to learn more about provider behaviors when interacting with patients. This information could provide an understanding of how the better providers fulfill patient needs for information and treat their patients with empathy and respect. With large enough databases, it should be possible to assess differences in factors predicting satisfaction by type of cancer and type of treatment. If there are differences, then it may be possible to increase patient satisfaction by targeting efforts to a class of patients rather than more broadly. Crossinstitutional and cross-national efforts should be encouraged to learn how factors unique to an institution or location influence, if at all, patient satisfaction. Ideally, longitudinal data should be collected, following the same patient over time and recording satisfaction at regular intervals. This will allow for more sophisticated statistical models and, critically, allow causal models to be developed that can more robustly determine the direct and indirect influences on patient satisfaction.

\section{Disclosures}

The authors report no conflicts of interest in this work.

\section{References}

1. Kleeberg UR, Feyer P, Gunther W, Behrens M. Patient satisfaction in outpatient cancer care: a prospective survey using The PASQOC(R) questionnaire. Support Care Cancer. 2008;16:947-954.

2. Williams B, Coyle J, Healy D. The meaning of patient satisfaction: an explanation of high reported levels. Soc Sci Med. 1998;47:1351-1359.
3. McClement SE, Hack TF. Audio-taping the oncology treatment consultation: a literature review. Patient Educ Couns. 1999;36:229-238.

4. Stiefel F, Razavi D. Common psychiatric disorders in cancer patients. II. Anxiety and acute confusional states. Support Care Cancer. 1994;2:233-237.

5. Stefanek ME, Derogatis LP, Shaw A. Psychological distress among oncology outpatients. Prevalence and severity as measured with the Brief Symptom Inventory. Psychosomatics. 1987;28:530-539.

6. von Gruenigen VE, Hutchins JR, Reidy AM, et al. Gynecologic oncology patients' satisfaction and symptom severity during palliative chemotherapy. Health Qual Life Outcomes. 2006;4:84.

7. Thomas S, Glynne-Jones R, Chait I. Is it worth the wait? A survey of patients' satisfaction with an oncology outpatient clinic. Eur J Cancer Care (Engl). 1997;6:50-58.

8. Apolone G, Mosconi P. Satisfaction surveys: do we really need new questionnaires? Int J Qual Health Care. 2005;17:463-464.

9. Sitzia J. How valid and reliable are patient satisfaction data? An analysis of 195 studies. Int J Qual Health Care. 1999;11:319-328.

10. Cleary PD. The increasing importance of patient surveys. Now that sound methods exist, patient surveys can facilitate improvement. $B M J$. 1999;319:720-721.

11. Bredart A, Mignot V, Rousseau A, et al. Validation of the EORTC QLQSAT32 cancer inpatient satisfaction questionnaire by self- versus interviewassessment comparison. Patient Educ Couns. 2004;54:207-212.

12. Kleeberg UR, Tews JT, Ruprecht T, et al. Patient satisfaction and quality of life in cancer outpatients: results of the PASQOC study. Support Care Cancer. 2005;13:303-310.

13. Groff SL, Carlson LE, Tsang K, Potter BJ. Cancer patients' satisfaction with care in traditional and innovative ambulatory oncology clinics. J Nurs Care Qual. 2008;23:251-257.

14. Landen CN Jr, Younger NO, Collins Sharp BA, Underwood PB. Cancer patients' satisfaction with physicians: Princess Margaret Hospital Satisfaction with Doctor Questionnaire results. Am J Obstet Gynecol. 2003;188:1177-1179.

15. Feyer P, Kleeberg UR, Steingraber M, Gunther W, Behrens M. Frequency of side effects in outpatient cancer care and their influence on patient satisfaction-a prospective survey using the PASQOC(R) questionnaire. Support Care Cancer. 2008;16:567-575.

16. Skarstein J, Dahl AA, Laading J, Fossa SD. Patient satisfaction in hospitalized cancer patients. Acta Oncol. 2002;41:639-645.

17. Kavadas V, Barham CP, Finch-Jones MD, et al. Assessment of satisfaction with care after inpatient treatment for oesophageal and gastric cancer. Br J Surg. 2004;91:719-723.

18. Bergenmar M, Nylen U, Lidbrink E, Bergh J, Brandberg Y. Improvements in patient satisfaction at an outpatient clinic for patients with breast cancer. Acta Oncol. 2006;45:550-558.

19. Defossez G, Mathoulin-Pelissier S, Ingrand I, et al. Satisfaction with care among patients with non-metastatic breast cancer: development and first steps of validation of the REPERES-60 questionnaire. $B M C$ Cancer. 2007;7:129.

20. Mathiesen TP, Willaing I, Freil M, et al. How do patients with colorectal cancer perceive treatment and care compared with the treating health care professionals? Med Care. 2007;45:394-400.

21. Sherlaw-Johnson C, Datta P, McCarthy M. Hospital differences in patient satisfaction with care for breast, colorectal, lung and prostate cancers. Eur J Cancer. 2008;44(11):1559-1565.

22. Vashisht A, Domoney CL, Handscomb K, Smith JR, Bridges JE. Patient satisfaction with the care provided at a gynaecology oncology clinic. J Obstet Gynaecol. 2000;20:183-184.

23. Avery KN, Metcalfe C, Nicklin J, et al. Satisfaction with care: an independent outcome measure in surgical oncology. Ann Surg Oncol. 2006; $13: 817-822$.

24. Egan M, Dowling M. Patients' satisfaction with a nurse-led oncology service. Br J Nurs. 2005;14:1112-1116.

25. Gesell SB, Gregory N. Identifying priority actions for improving patient satisfaction with outpatient cancer care. J Nurs Care Qual. 2004;19:226-233. 
26. Bredart A, Razavi D, Robertson C, et al. Assessment of quality of care in an oncology institute using information on patients' satisfaction. Oncology. 2001;61:120-128.

27. Wiggers JH, Donovan KO, Redman S, Sanson-Fisher RW. Cancer patient satisfaction with care. Cancer. 1990;66:610-616.

28. Brown RF, Hill C, Burant CJ, Siminoff LA. Satisfaction of early breast cancer patients with discussions during initial oncology consultations with a medical oncologist. Psychooncology. 2009;18:42-49.

29. Zissiadis Y, Provis A, Harper E, et al. Patient satisfaction in radiation oncology. Australas Radiol. 2006;50:455-462.

30. Davidson R, Mills ME. Cancer patients' satisfaction with communication, information and quality of care in a UK region. Eur J Cancer Care (Engl). 2005;14:83-90.

31. Gourdji I, McVey L, Loiselle C. Patients' satisfaction and importance ratings of quality in an outpatient oncology center. J Nurs Care Qual. 2003;18:43-55.

32. McNamara S, Brown J. An audit of patient satisfaction with a NeuroOncology clinic. Eur J Oncol Nurs. 2003;7:200-203.

33. Fossa SD, Hjermstad MJ, Mork IH, Hjortdahl P. Does the service at a large oncologic out-patient clinic satisfy the patients' perceived need? Int J Health Care Qual Assur. 1996;9:24-29.

34. Ishikawa H, Takayama T, Yamazaki Y, Seki Y, Katsumata N. Physicianpatient communication and patient satisfaction in Japanese cancer consultations. Soc Sci Med. 2002;55:301-311.

35. Quinn GP, Jacobsen PB, Albrecht TL, et al. Real-time patient satisfaction survey and improvement process. Hosp Top. 2004;82:26-32.

36. Isenring E, Capra S, Bauer J. Patient satisfaction is rated higher by radiation oncology outpatients receiving nutrition intervention compared with usual care. J Hum Nutr Diet. 2004;17:145-152.

37. Koinberg I, Holmberg L, Fridlund B. Satisfaction with routine follow-up visits to the physician - the needs of patients with breast cancer. Acta Oncol. 2001;40:454-459.

38. Gallant MD, Coutts LM. Evaluation of an oncology outpatient orientation program: patient satisfaction and outcomes. Support Care Cancer. 2003;11:800-805.

39. Bredart A, Robertson C, Razavi D, et al. Patients' satisfaction ratings and their desire for care improvement across oncology settings from France, Italy, Poland and Sweden. Psychooncology. 2003;12:68-77.

40. D' haese S, Vinh-Hung V, Bijdekerke P, et al. The effect of timing of the provision of information on anxiety and satisfaction of cancer patients receiving radiotherapy. J Cancer Educ. 2000;15:223-227.

41. Grunfeld E, Fitzpatrick R, Mant D, et al. Comparison of breast cancer patient satisfaction with follow-up in primary care versus specialist care: results from a randomized controlled trial. Br J Gen Pract. 1999;49:705-710.

42. Sandoval GA, Brown AD, Sullivan T, Green E. Factors that influence cancer patients' overall perceptions of the quality of care. Int J Qual Health Care. 2006;18:266-274.

43. Haggmark C, Bohman L, Ilmoni-Brandt K, et al. Effects of information supply on satisfaction with information and quality of life in cancer patients receiving curative radiation therapy. Patient Educ Couns. 2001;45:173-179.

44. Ong LM, Visser MR, Lammes FB, de Haes JC. Doctor-patient communication and cancer patients' quality of life and satisfaction. Patient Educ Couns. 2000;41:145-156.

45. Can G, Akin S, Aydiner A, Ozdilli K, Durna Z. Evaluation of the effect of care given by nursing students on oncology patients' satisfaction. Eur J Oncol Nurs. 2008;12:387-392.

Patient Preference and Adherence

\section{Publish your work in this journal}

Patient Preference and Adherence is an international, peer-reviewed, open access journal that focusing on the growing importance of patient preference and adherence throughout the therapeutic continuum. Patient satisfaction, acceptability, quality of life, compliance, persistence and their role in developing new therapeutic modalities and compounds to
46. Bredart A, Coens C, Aaronson N, et al. Determinants of patient satisfaction in oncology settings from European and Asian countries: preliminary results based on the EORTC IN-PATSAT32 questionnaire. Eur J Cancer. 2007;43:323-330.

47. Sandoval GA, Levinton C, Blackstien-Hirsch P, Brown AD. Selecting predictors of cancer patients' overall perceptions of the quality of care received. Ann Oncol. 2006;17:151-156.

48. Liekweg A, Eckhardt M, Taylor SC, Erdfelder E, Jaehde U. Psychometric assessment and application of a questionnaire measuring patient: satisfaction with information on cancer treatment. Pharm World Sci. 2005;27:96-103.

49. Walker MS, Ristvedt SL, Haughey BH. Patient care in multidisciplinary cancer clinics: does attention to psychosocial needs predict patient satisfaction? Psychooncology. 2003;12:291-300.

50. Eide H, Graugaard P, Holgersen K, Finset A. Physician communication in different phases of a consultation at an oncology outpatient clinic related to patient satisfaction. Patient Educ Couns. 2003;51: 259-266.

51. Jones R, Pearson J, McGregor S, et al. Cross sectional survey of patients' satisfaction with information about cancer. BMJ. 1999;319: 1247-1248.

52. Blanchard CG, Labrecque MS, Ruckdeschel JC, Blanchard EB. Physician behaviors, patient perceptions, and patient characteristics as predictors of satisfaction of hospitalized adult cancer patients. Cancer. 1990;65:186-192.

53. Bitar R, Bezjak A, Mah K, et al. Does tumor status influence cancer patients' satisfaction with the doctor-patient interaction? Support Care Cancer. 2004;12:34-40.

54. Blanchard CG, Ruckdeschel JC, Fletcher BA, Blanchard EB. The impact of oncologists' behaviors on patient satisfaction with morning rounds. Cancer. 1986;58:387-393.

55. Bredart A, Bouleuc C, Dolbeault S. Doctor-patient communication and satisfaction with care in oncology. Curr Opin Oncol. 2005;17: 351-354.

56. Jansen SJ, Otten W, van de Velde CJ, Nortier JW, Stiggelbout AM. The impact of the perception of treatment choice on satisfaction with treatment, experienced chemotherapy burden and current quality of life. Br J Cancer. 2004;91:56-61.

57. Poroch D. The effect of preparatory patient education on the anxiety and satisfaction of cancer patients receiving radiation therapy. Cancer Nurs. 1995;18:206-214.

58. Crow R, Gage H, Hampson S, et al. The measurement of satisfaction with healthcare: implications for practice from a systematic review of the literature. Health Technol Assess. 2002;6:1-244.

59. Bolus R, Pitts J. Patient satisfaction: the indispensable outcome. Manag Care. 1999;8:24-28.

60. Hill J. Patient satisfaction in a nurse-led rheumatology clinic. $J A d v$ Nurs. 1997;25:347-354.

61. Thomas R, Kaminski E, Stanton E, Williams M. Measuring information strategies in oncology - developing an information satisfaction questionnaire. Eur J Cancer Care (Engl). 2004;13:65-70.

62. Cheater FM, Preston C, Wynn A, Hearnshaw H, Baker R. Patients' views of cancer services: development of a questionnaire for accreditation. Eur J Oncol Nurs. 1999;3:72-82.

63. Hall JA, Epstein AM, DeCiantis ML, McNeil BJ. Physicians' liking for their patients: more evidence for the role of affect in medical care. Health Psychol. 1993;12:140-146.

optimize clinical outcomes for existing disease states are major areas of interest. This journal has been accepted for indexing on PubMed Central. The manuscript management system is completely online and includes a very quick and fair peer-review system. Visit http://www.dovepress.com/ testimonials.php to read real quotes from published authors. 